\title{
Lecciones de metodología de un politólogo intelectual
}

\author{
RUBÉN SÁNCHEZ DAVID*
}

La muerte de Giovanni Sartori privó a la comunidad intelectual de un académico erudito, ecléctico y comprometido, cuya vida y obra lo convirtieron en un referente destacado de la ciencia política, comprometido con la libertad de expresión y la crítica.

Testigo de violentos conflictos bélicos e ideológicos, fue un defensor acérrimo de la democracia y del estudio metódico de la ciencia política como disciplina autónoma, basada en un lenguaje preciso y un método riguroso ligada estrechamente a la teoría política. Desde su punto de vista, la teoría política es inseparable del método de la ciencia de las modalidades, para recopilar informaciones y analizarlas, por lo que no se puede hablar del uno sin hablar también de la otra, lo cual conduce a prestar especial atención a la formación de los conceptos.

Para Sartori la disciplina de la ciencia política oscila actualmente, entre dos extremos equivocados. Por un lado, una mayoría de politólogos que confunden método con técnicas y, por otro, una sofisticada minoría, cuyas referencias teóricas y metodológicas proceden de las ciencias físicas (Sartori, 2011, p. 15). Para él, la metodología es más que manipulación de datos; no puede haber metodología sin logos, sin un pensamiento habituado a pensar lógicamente, consciente de sus límites pero que desborde lo micro, lo mensurable, lo visible y no pierda de vista el contexto general y la historia social. En este sentido, hablar de política es tener en cuenta lo social, lo económico, lo moral y lo religioso. De allí que no marginara lo normativo y viera con recelo los postulados conductistas, estructuralistas y cuantitativistas que intentan dar una explicación causal a

\footnotetext{
* Profesor titular de la Facultad de Ciencia Política, Gobierno y Relaciones Internacionales de la Universidad del Rosario, Bogotá, Colombia. Correo electrónico: ruben.sanchez@, urosario.edu.co
} 
través de meros datos y cifras. En sus términos, una ciencia política empírica que no esté guiada por la teoría política, es una ciencia política ciega condenada a la irrelevancia científica, presa entre la filosofía política, por un lado, y la acción política, por otro.

Para entender el porqué de la relación estrecha entre teoría política y su propuesta metodológica es importante tener presente el momento histórico en que despliega su concepción y la distancia que toma frente a la revolución conductista. Ciertamente, el conductismo hizo de la ciencia política una ciencia empírica interesada en estudiar los comportamientos políticos, trascendiendo los aspectos jurídicos y formales de la política, y Sartori lo reconoce. Sin embargo, también reacciona ante la ausencia de teoría de una parte relevante del conductismo, que revela la falta de rigor con que algunos cientistas políticos manejan los conceptos.

De acuerdo con Sartori sin un correcto uso del lenguaje y sin definiciones claras la ciencia, y en particular la ciencia política, no construye sino una torre de Babel. Por ello, el primer problema es distinguir entre el lenguaje ordinario y los lenguajes especializados. Negar además que todas las ciencias provienen de la filosofía es negar el origen de su propia existencia. En este sentido, el estudio de los clásicos no puede ser excluido de la reflexión teórica, sin perder de vista que no se puede confundir el lenguaje que tiene una finalidad empírica y científica, del lenguaje especulativo propio de la filosofía, dado que los conceptos son "recolectores de hechos". En consecuencia, la primera tarea de la ciencia es manejar conceptos exentos de ambigüedad, de modo que puedan ser operacionalizados adecuadamente. Esta tarea conduce directamente a una labor de clasificación y a establecer escalas de abstracción que permitan diferenciar acertadamente distintos niveles de análisis y contar con instrumentos adecuados de clasificación y comparación. En otros términos, no se pueden hacer buenas comparaciones si no se relativiza el factor contextual y para ello hay que ubicar correctamente los conceptos en los sistemas conceptuales a los que pertenecen.

El enfoque adoptado por Sartori (2011) lo lleva a considerar que en la ciencia política no caben las teorías generales y que las teorías 
adecuadas son las de rango medio, donde es posible hacer comparaciones más o menos homogéneas. Su ejemplificación más clara se encuentra en su teoría sobre sistemas de partidos. En este orden de ideas, hacer teoría política es partir de una escala alta de abstracción y descender gradualmente a lo largo de la escala hasta afinar los conceptos de modo que se puedan generalizar y manejar categorías empíricamente controlables. Así lo demostró en los campos de su interés: el método de la ciencia política, la teoría de la democracia y las instituciones políticas como partidos y estructuras constitucionales.

En suma, Sartori considera que una vez definidos los conceptos con precisión, se puede proceder a la cuantificación sin perder de vista que no todos los fenómenos políticos pueden ser analizados, explicados e interpretados adecuadamente, valiéndose de herramientas y fórmulas matemáticas. En esta labor la precisión en el lenguaje es esencial en la medida en que todo el proceso de conocimiento comienza por nombrar.

\section{Referencias}

Sartori, G. (2011). Como hacer ciencia política. Madrid: Taurus. 